\title{
0 desafio da malária: o caso brasileiro e o que se pode esperar dos progressos da era genômica
}

The malaria challenge: the Brazilian case and what can be expected from progress in genomics

Luiz Hildebrando Pereira da Silva 1

Vera Engracia Gama de Oliveira

\begin{abstract}
M alaria endemic areas in Brazil are restricted to the Amazon Region, with an average of 500 thousand new cases every year. The situation can be defined as unstable hipoendemic with, however, foci of high endemicity. Demographic and socio economic factors are main determinants in the malaria challenge for the Public $\mathrm{H}$ ealth System. In the present paper, bi ological and social factors responsible for the unstable endemic situation are discussed. The need for a permanent surveillance and intervention of Public H ealth Services are stressed to avoid the occurrence of local epidemics and spreading of endemic areas. In the paper, are also summarised recent lines of research developed in the post genomic era in the studies of parasite, vector and human molecular genetics that would favour the development, in the future, of new tools and procedures for malaria control
\end{abstract}

Key words M alaria, Genomics, Plasmodium, Anopheles
Resumo $\mathrm{A}$ área endêmica demalária no Brasil se estende atualmente à totalidade da região amazônica, com cerca de 500 mil casos anuais, em geral com situações de baixa e mé dia endemicidade mas ainda apresentando focos de alto risco. Fatores demográficos e socioeconômi cos são dominantes nos desafios que enfrentam os Serviços de Saúde Pública no controle da malária. No presente artigo são discutidos fatores determinantes da instabilidade da situação endêmica bem como a necessidade de ações permanentes de vigilância e de interven ção dos Servi ços de Saú de para que se evitem surtos epi dêmi cos e alastramento das áreas endêmicas. No artigo, em seguida, apresenta-se uma síntese de progressos recentes nos estudos da era genômica e pós- genômica sobre o parasita, o vetor e o hospedei ro humano que podem favorecer, no futuro, o desenvolvimento ea melhoria dos métodos de controle da malária.

Palavras-chave M alária, Genomics, Plasmodium, Anopheles
1 Centro de Pesquisa em M edicina Tropical. Rodovia BR 364, Km 4,5 78970-900 Porto Velho RO. hildebrando@cepem.com.br 


\section{Introdução}

A malária no Brasil, no período anterior a 1940, cobria grande parte do território nacional e se constituía em verdadeiro desafio à coIonização não apenas da Amazônia mas de várias áreas litorâneas do sudeste e de áreas da bacia dos rios Paraná-Prata, São Francisco e Doce, no Planalto Central. Sem se dispor de re gistro confiável de incidência, avaliava-se que 0 número de casos anuais de malária oscilava em torno de 4 a 5 milhões (Pessoa, 1946). Na primeira metade do século 20 , a malária provocou dois episódios dramáticos de grandes dimensões: o primeiro, durante a construção da Ferrovia $M$ adeira-M amoré, no início do século, quando se calcula que tenha provocado mais de 10 mil mortes entre trabal hadores, nas várias etapas da sua abertura e implantação. 0 se gundo, no Nordeste brasileiro, na década de 1930, após a chegada nas costas brasileiras, por meio das lanchas rápidas entre Dakar e N atal, do mosquito africano Anopheles gambiae, exce lente vetor adaptado às regiões semi-áridas do Sahel africano. A penetração do A. gambiae no N ordeste brasileiro provocou uma terrível epidemia nas áreas rurais, com cerca de $14 \mathrm{mil}$ mortes nos anos 1938-1939 (Deane, 1988). Re gistre se o fato de que a campanha contra o $\mathrm{A}$. gambiae, comandada pelo entomologista americano Fred Soper, da Fundação Rockefeller, conseguiu, em apenas 14 meses, a façanha de erradicar esse anofelino da região nordestina. I sso numa época anterior ao DDT, em que os meios de combate ao mosquito eram restritos aos inseticidas à base de piretro e os larvicidas químicos à base de arsenicais como o verde $\mathrm{Pa}$ ris (Soper \& Wilson, 1943).

O Serviço $N$ acional de M alária (criado em 1941) implantou no país, a partir dos anos 1950, a estratégia de "erradicação" como parte de campanha internacional, sob a égide da Organização M undial da Saúde. Essa estratégia baseava-se no uso de inseticidas de ação residual (o DDT em particular) e das novas drogas antimaláricas sintéticas, em particular as quatro aminoquinoleínas (cloroquina). A campanha teve grande sucesso, permitindo erradicar a malária de quase toda a área litorânea do país (com exceção de uma faixa na área da serra do M ar de Paraná-Santa Catarina), e das regiões tributárias das grandes bacias hidrográficas do país fora da Amazônia (D eane, 1992).

No início da década de 1960, o número de casos de malária caíra a apenas cerca de 40.000 por ano (Figura 1), concentrados na região amazônica, onde a extensão das áreas, as dificuldades de acesso, a dispersão e a natureza das habitações não permitiam o uso apropriado de inseticidas (M arques e Gutierrez, 1993). Entretanto, com o desenvolvimento dos projetos de colonização da Amazônia pelo governo militar, a partir dos meados da década de 1960, verificou-se um enorme processo migratório para a região, que recebeu, entre 1970 e1980, mais de 1 milhão de imigrantes, do sul, sudeste e nordeste do país (M arques, 1987). O s imigrantes, em áreas rurais, implantaram assentamentos agrícolas e desenvolveram intensa atividade de garimpo a céu aberto, ocasionando vastas ações de desflorestamento, perturbação dos cursos naturais de rios, igarapés e lagos, criando, assim, condições favoráveis à proliferação dos anofelinos. Some-se a isso as precárias condições de habitação e a total inexperiência em malária, pois provinham de áreas do país onde a malária nunca existira, ou fora erradicada havia mais de 20 anos. Esses fatores, associados ainda à insuficiência de estruturas médico-sanitárias, levaram ao desencadeamento do terceiro drama de malária do século no país. Dessa vez, entretanto, o drama atingiu proporções continentais, em toda a Amazônia e, devido à movimentação dos migrantes aos locais de origem, provocou o reaparecimento de focos de malária em regiões onde ela tinha sido erradicada nas campanhas de 1950-1960 (Deane, 1992).

0 número anual de casos novos de malária no país saltou assim de 39.729 em 1960 para mais de 100 mil em 1965 e 170 mil em 1980, continuando a crescer na década de 1980 para atingir um platô em torno dos 500 mil em 1990. A partir dessa data vem flutuando em torno dos 500 mil casos anuais (Figura 1). Essa estabilização reflete um certo equilíbrio obtido com as medidas de controle desenvolvidas pelo M inistério da Saúde, em particular a multiplicação de postos de atendimento, restrições impostas ao desenvolvimento de garimpos a céu aberto e maior controle nas condições de implantação de assentamentos agrícolas. A mortalidade por malária, que era relativamente elevada na década dos 1980 (nível de 1.500 anuais), caiu para cerca de 150 na década de 1990 e mantém-se neste nível (Funasa, 2000). 0 equilíbrio, entretanto, é extremamente frágil, como demonstra a oscilação das cifras observadas na curva de incidência anual da figura 1, fruto de variações climáticas, movimentos demográficos e sociais e deslocamentos populacionais 
Figura 1

Evolução do número de casos de malária no Brasil de 1960 a 2001.

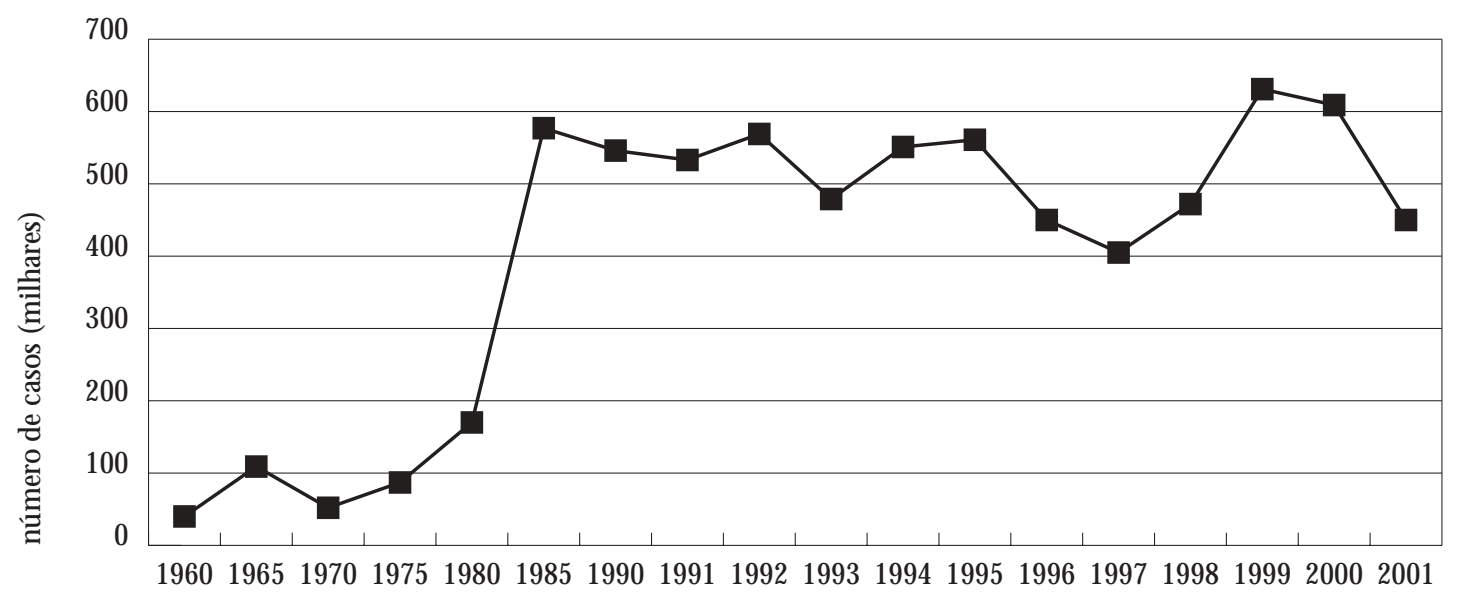

1960-1990 - variação quinquenal.

1990-2001 - variação anual.

Fonte: Funasa, 2001 e Funasa, comunicação aos autores.

imprevistos. Ainda recentemente, no ano de 1999, observou-se um súbito aumento no número de casos, que passou de cerca de $470 \mathrm{mil}$ em 1998 a 630 mil em 1999. As medidas de reação do M inistério da Saúde, responsável pela implantação do Plano de Incremento de Ações de Controle da M alária (Funasa, 2000), deram bons resultados, registrando-se ligeiro recuo no número de casos no ano 2000 (em torno de $600 \mathrm{mil}$ ) e uma nítida tendência à queda no ano de 2001. Esses resultados demonstram, de um lado, a capacidade dos serviços de saúde do país em impor medidas de controle eficazes, permitindo obter reduções nas taxas de incidência. Por outro lado, el es revelam a instabilidade e a fragilidade dessas mesmas medidas de controle que exigem vigilância permanente e investimentos constantes. Sem o atendimento dessa exigência, é iminente o risco de reversões de situações e de surgimento de novos surtos epidêmicos.

A situação de malária do país, no início do século 21, define-se portanto como uma situação de "malária residual", estendendo-se praticamente a toda região amazônica, com predominância da malária vivax, que atinge $70 \%$ ou mais dos casos, com níveis de endemicidade baixa ou média, mas com alguns focos de incidência elevada (alto risco). A situação se caracteriza ainda por alta instabilidade e permanente ameaça: a desenvolver surtos epidêmicos, alastrar-se a regiões vizinhas, provocar metástases focais em outras regiões do país e a estar sujeita a largas oscilações em função de variáveis climáticas, demográficas ou socioeconômicas. Esse éo desafio atual da malária no Brasil.

É interessante assinalar que os progressos nos conhecimentos científicos na área da biomedicina, que foram importantes no século 20 e espetaculares nas últimas décadas, tiveram pouco impacto nos métodos de controle da malária. Eles continuam a se basear essencialmente nos métodos do fim do século 19, a saber, controle de vetores por inseticidas e larvicidas e tratamento de doentes, portadores de parasitas.

Em relação às grandes patologias que afetam o homem desde a antigüidade, a malária oferece portanto um quadro paradoxal: na época atual, quando se começa a obter sucessos no tratamento do câncer e se abrem perspectivas de terapia gênica, a malária continua a afetar dramaticamente grande parte da humanidade no hemisfério sul; seu controle é ainda baseado em métodos do século 19; e sua incidência pouco recuou, parecendo, ao contrário, aumentar em volume e gravidade. É legítimo, portanto, interrogar-se se os progressos da era genômica poderão repercutir no desenvolvimento de novos métodos de controle. Haverá novas soluções para eliminar a malária residual em situa- 
ções como a do Brasil? Haverá novas soluções para controlar ou ao menos reduzir a situação brutal da malária africana com os seus $2 \mathrm{mi}$ Ihões de mortes anuais de crianças?

No presente trabalho, procuramos dar uma visão sintética de novos conhecimentos que a era genômica vem permitindo desenvolver sobre a "genética da malária". Pretendemos assinalar as linhas de pesquisas que vêm se desenvolvendo com maior intensidade e com perspectivas mais promissoras. Até o momento, esses estudos não se traduziram por aplicações importantes. Entretanto, há o sentimento que se generaliza entre os pesquisadores de que os 20 anos de esforços empen hados até hoje começam a dar frutos e a amadurecer soluções.

\section{A "genética da malária"}

A malária é provocada por protozoários parasitas da ordem A picomplexa e gênero Plasmodium que fazem parte do grupo dos coccídeos, com ciclos complexos de multiplicação sexuada e assexuada. As quatro espécies de plasmódios que infectam o homem, $P$. falciparum, $P$. vivax, P. malariae e P. ovale (este último ausente do Brasil), são transmitidas por mosquitos do gênero Anopheles. Os parasitas da malária têm alto nível de especificidade de hospedeiros, resultante de um longo processo de adaptação no curso da evolução. Assim, os parasitas da malária humana são específicos do homem. Embora possam infectar outros primatas em laboratório, não são normalmente encontrados em condições naturais. Faz exceção P. malariae, que é encontrado em primatas da região neotropical sob a forma do denominado P. brasilianum. Por outro lado, os plasmódios não infectam qualquer anofelino. Entre as centenas de espécies do gênero, poucas dezenas são vetores eficazes e, nas diversas áreas geográficas, as espécies presentes de anofelinos têm diferentes capacidades vetoriais pelas diferentes espécies de Plasmodium presentes. A "genética da malária" implica portanto uma interação entre "três genéticas": genética do hospedeiro humano, a genética do parasita e a genética do vetor. Em cada caso, analisam-se os fatores que definem as especificidades das interações.

Fatores genéticos humanos relacionados com a susceptibilidade à malária

A alta prevalência, em determinadas re- giões do globo terrestre, de alelos deletérios de proteínas eritrocitárias, estimulou estudos sobre a manutenção desses alelos por vantagens seletivas. Um esboço da influência das doenças infecciosas na constituição do genoma humano foi feito por A. E. Garrod em 1931, que no seu livro The inborn factors in disease sugere que as doenças infecciosas podem ter exercido grande força seletiva no modelamento da individualidade bioquímica. Outra contribuição importante foi dada por H aldane (1948), que, sugerindo vantagem do heterozigoto de talassemias em determinados grupos populacionais, abriu um campo de investigação de suscetibilidade genética à infecção. M uitos dos trabalhos surgidos nos últimos anos sobre malária têm importantes implicações, tanto para a compreensão da patogênese como para controle da doença. 0 polimorfismo do gene da cadeia $b$ da Globina de Hemoglobina, mantido por mecanismos de polimorfismo balanceado, foi o primeiro a ser correlacionado com resistência a formas graves de malária falcípara (Allison, 1954). Trabalhos de Hill et al. (1991), em crianças do oeste africano, sugeriram que haplótipos do sistema de antígenos leucocitários HLA da classe I (HLA-Bw53) e um da classe II (DRB1*1302-DQB1*0501), comuns nesta região da África, mas raros em outros grupos populacionais, estavam independentemente associados com proteção contra a malária cerebral e anemia severa, respectivamente. De um modo geral, as associações das classes I ell do sistema H LA atuariam através da seleção diferencial de epítopes peptídeos particulares de um patógeno para apresentação aos linfócitos $T$. Segundo Hill et al., 1992, as associações HLAB53 com malária eram um exemplo de como essa associação se processava, através da identificação de linfócitos T citotóxicos reconhecendo HLA-B53 e um epítope particular do parasita. Entretanto, estudos de terreno de outras equipes de pesquisadores (Dieye et al., 1997 comunicação pessoal de $\mathrm{P}$ Druilhe aos autores) contrariam as hipóteses de H ill. O utra associação relacionada à malária envolve o gene codificador do Fator de N ecrose Tumoral (TNF). Estudos de M cGuire (ver M cGuire et al., 1999, para revisão) em crianças gambienses demonstraram que as que são homozigotas para a mutação puntual na posição - 308 da região promotora do TNF apresentaram risco significantemente aumentado de óbito por malária cerebral e que a anemia severa devido à malária estava associada à mutação na posição - 238. 0 
fato de a malária cerebral estar associada ao alelo TNF-308 A e de a anemia severa ao alelo TNF-238 A levou o grupo de M cGuire a sugerir que a manifestação clínica da malária é influenciada por determinantes genéticos complexos local izados próximos ao gene TNF. Foram identificados diversos al elos do sistema HLA em desequilíbrio de ligação com o alelo TNF-238, mas nenhum deles foi responsável pela asso ciação com suscetibilidade à anemia severa. 0 impasse, segundo os autores, necessita de estudos em populações geneticamente distintas, além de estudos em grupos familiais, para definição precisa dos elementos genéticos envolvidos. A resistência inata ao Plasmodium falciparum é dada por características genéticas que afetam vários estágios do ciclo intraeritrocitário do plasmódio. As mutações eritrocitárias principais que conferem proteção contra a malária caracterizam-se por aumento de radicais livres de Oxigênio (como nas anemias falciformes, causada pelo al elo $\mathrm{HbS}$ em homozigose) ou pelo decréscimo na habilidade em lidar com danos oxidantes, como nas deficiências da enzima G licose-6-fosfato desidrogenase (G6PD) (Nagel, 1990). Discutiremos brevemente estes dois polimorfismos genéticos na malária falcípara e o sistema sangüíneo Duffy, cujo polimorfismo está associado a resistência à malária vivax.

Hemoglobina S - A habilidade para resistência ao $P$. falciparum é um traço adaptativo importante das populações humanas que vivem em áreas endêmicas. Proteínas de membranas eritrocitárias atuam como mediadoras de adesão pelos eritrócitos infectados às células endoteliais. Supõe-se que o desenvolvimento e sobrevivência de gametócitos intraeritrocitários depende fortemente da habilidade de as células infectadas seqüestrarem na microvascularização de vários órgãos. A adesão e seqüestração de eritrócitos infectados pode levar a formas graves de malária, como a malária cerebral. Destro-Bisol et al. (1999a) propuseram que a interação entre $\mathrm{Hb}$ oxidada e proteínas de membrana eritrocitárias é um mecanismo celular importante para que a variante $S$ do loco da cadeia $\beta$ da $\mathrm{H}$ b produza resistência ao $P$. falciparum, sendo a destruição acelerada de eritrócitos parasitados um dos mecanismos pelos quais portadores de $\mathrm{HbS}$ conseguem proteção contra P. falciparum (Telen, 2000, para revisão). 0 padrão irreversível de interação hemoglobina-membrana poderia desencadear mecanismos que: 1) reduzem a invasão dos eritróci- tos pelo $P$. falciparum; 2) dificultam a sobrevivência do parasita e seu desenvolvimento na célula; e 3) aceleram a fagocitose das células infectadas. $\mathrm{O}$ surgimento do al elo $\mathrm{S}$ da $\mathrm{H}$ emoglobina deu-se pela mutação no sexto codon do gene $\beta$, em que GAG étrocado por GTG, levando à produção do aminoácido Valina no lugar do ácido Glutâmico. Em heterozigose (genótipo $\mathrm{HBB} * \mathrm{~A} / * \mathrm{~S}$ ) haveria proteção contra as formas graves da malária falcípara (ver AshleyKoch et al., 2000, para revisão). Luzzatto et al., 1970 demonstraram in vitro que o produto do alelo GPX $1 * 2$, do sistema Glutatião peroxi dase eritrocitário (GPX1; EC 1.11.1.9), que catalisa a oxidação do Glutatião reduzido (GSH) por peróxido de Hidrogênio $\left(\mathrm{H}_{2} \mathrm{O}_{2}\right)$ e outros peróxidos, interfere com a habilidade de as células $\mathrm{H} B \mathrm{~B}^{*} \mathrm{~A} /{ }^{*} \mathrm{~S}$ limitarem a invasão e crescimento do parasita $P$. falciparum. $A$ alta atividade peroxidásica do produto do alelo GPX1*2 poderia interferir nas modificações da membrana do eritrócito, que causam o efeito antimalárico do genótipo $\mathrm{HBB}^{*} \mathrm{~A} / * \mathrm{~S}$, provocando um efeito epistático, pelo decréscimo da proteção deste genótipo contra a malária fal cípara. Destro-Bisol et al. (1999b) propuseram a hipótese de que em nível clínico espera-se encontrar um aumento significante de portadores do alelo GPX $1 * 2$ entre os indivíduos $\mathrm{HBB} \mathrm{B} / *$ S que desenvolvem malária severa. M odiano et al. (1996a, b) não encontraram correlação entre o traço falcêmico e vantagem seletiva ao estudarem três grupos étnicos do oeste africano. Entretanto, no mesmo contexto epidemiológico, alguns indivíduos caracterizaram-se por apresentar reatividade imunológica diferenciada, evidenciando diferenças interétnicas na suscetibilidade ao $P$. falciparum, que envolviam provavelmente regulação genética na resposta imune humoral (menor parasitemia, maior resposta a todos antígenos testados). Posteriormente, M odiano et al. (2001) concluíram que a menor suscetibilidade do grupo Fulani, nômades em via de assentamento, e de provável origem caucasiana (os outros dois grupos étnicos eram de camponeses, assentados, e de origem negróide), devia-se realmente a fatores genéticos de resistência desconhecidos, provavel mente envolvidos na regulação da resposta imune humoral. N um estudo sobre mecanismos genéticos responsáveis pela resistência à malária efetuado numa região endêmica de Rondônia (Portuchuelo, vilarejo ribeirinho), Feitosa et al. (2001) sugerem a existência de um gene principal, codominante, e que devido à freqüência e ao modo 
de herança, parece ser independente dos polimorfismos de Hb, Fy ou G6PD. Em outro estudo, realizado em Burkina Faso, com 4.348 indivíduos (M ossi), M odiano et al. (2001) verificaram que $\mathrm{HbC}$ está associada com uma redução de $29 \%$ no risco para a manifestação clínica da malária nos indivíduos heterozigotos $\mathrm{HbAC}$ $(\mathrm{P}=0,0008)$ e de $93 \%$ nos homozigotos $\mathrm{H} \mathrm{bCC}$ $(P=0,0011)$. $O$ s autores sugerem que, a longo prazo e na ausência de controle para malária, $\mathrm{HbC}$ poderia substituir $\mathrm{HbS}$ na área central da África ocidental.

D esidrogenase de G licose-6-fosfato (G6PD) - Para seu desenvolvimento, o parasita aumenta consideravelmente sua necessidade metabólica, num período limitado de tempo, gerando um estresse adicional à célula hospedeira, levando-a à destruição. A membrana eritrocitária sofre modificações decorrentes desses processos oxidantes, levando a uma fagocitose acentuada dos eritrócitos em indivíduos thalassêmicos, com traço falcêmico e com deficiência em G6PD (Cappadoro et al., 1992). 0 gene da G6PD éligado ao cromossomo $X$ e apresenta numerosas mutações, que causam deficiência enzimática nos eritrócitos. Algumas dessas mutações existem em freqüência polimórfica e parecem apresentar vantagem seletiva, por conferirem resistência à malária falcípara. As mutações distribuem-se segundo populações e as mais comuns são G6PDA- (202A376G), comum na África, e G6PD Mediterrânea (563T), encontrada no sul da Europa, no Oriente médio e Índia. Alelos com baixa atividade enzimática ( $A$ - e $\left.A_{\text {med }}\right)$ levam à redução no risco de infecção por P. falciparum. Luzzatto \& N otaro (2001), em estudos sobre a história evolucionária da G6PD evidenciam a importância das análises moleculares, que mostram a conexão entre malária e deficiência em G6PD e propiciam vislumbrar um exemplo de coevolução do parasita e seu hospedeiro. Como argumento de que a deficiência em G6PD é selecionada positivamente pela malária, citam o fato de que existem mais de 130 variantes conhecidas de G6PD, e pelo menos 34 dessas são polimórficas. Todas a variantes polimórficas são encontradas em populações que vivem (ou viveram) em áreas endêmicas de malária. Salientam que ainda não foi possível explicar duas questões importantes na relação deficiência em G6PD/vantagem seletiva: 1) Como a deficiência em G6PD protege contra o P. falciparum e 2) Por que apenas as mulheres heterozigotas são protegidas ( havendo um impasse sobre se os homens hemizigo- tos são também protegidos)?

Em 1976, Miller et al. apresentaram evidências de que o fenótipo nulo de Duffy confere resistência à malária vivax, sendo os antígenos Duffy receptores para o segundo estágio de invasão dos eritrócitos pelo P. vivax (merozoítas, a forma sangüínea de invasão).

O sistema Duffy - Foi o primeiro grupo sangüíneo a ser determinado a um loco autossômico específico, o cromossomo 1 (D onahue, 1968). U ma forte ligação com alfa-espectrin sugeriu a localização de Duffy (Fy) na banda q21 (M cAlpine et al., 1989). A glicoproteína Duffy (Duffy GPP; gpFy) foi identificada primeiramente nos eritrócitos através de aloanticorpos encontrados no soro de um hemofílico politransfundido (Cutbush et al., 1950), que reconheceu 0 antígeno Fya. 0 antígeno Fyb foi descrito um ano depois (Ikin et al., 1951). A glicoproteína Duffy é composta por 338 aminoácidos, com peso molecular teórico de 35kD, sendo um receptor de membrana heptahelical (Hadley \& Peiper, 1997, para revisão).

Polimorfismo do sistema D uffy e malária 0 grupo sangüíneo Duffy é caracterizado por três alel os principais: $F{ }^{*} A$ e $F Y{ }^{*} B$, que diferem em um único nucleotídeo (G131A), havendo troca do aminoácido Gly por Asp no resíduo 44, no N-terminal do domínio extracelular da glicoproteína (M allison et al., 1995). Os genótipos decorrentes desses al elos codominantes são: $F Y^{*} A / F Y^{*} A, F Y * A / F Y * B$ e $F Y^{*} B /$ $F{ }^{*} B$, respectivamente. $A$ freqüência do alelo FY*A é proporcional à freqüência do alelo $\mathrm{FY} * \mathrm{~B}$ na Europa, chegando a quase $100 \%$ na Ásia. $\mathrm{O}$ terceiro alelo, $\mathrm{FY}^{*} \mathrm{O}$, corresponde ao fenótipo sorológico $F y(a-b-)$, isto é, à ausência do antígeno (fenótipo nulo). A maioria dos africanos ocidentais e cerca de $68 \%$ dos negros americanos não expressam os antígenos Fya ou Fyb em seus eritrócitos (M ourant et al., 1976). Tournamille et al. (1995) encontraram uma mutação no gene Duffy de indivíduos Fy (a-b-) negro que não estava na regi ão codificadora do gene, mas na região promotora upstream ao códon metionina de tradução/iniciação. A seqüência TTATCT está presente nos alelos $\mathrm{A} e$ $B$, e éuma seqüência consenso para ligação com fatores GATA de transcrição. Esta seqüência é mutada para TTACCT no fator GATA-1 específico para o eritrócito. Consequentemente, há a inibição do gene no tecido hematopoético, mas não nos outros tecidos. Parasol et al. (1998) descobriram que em alguns casos indivíduos Fy (b-) apresentam o tipo selvagem FY*B GATA 
mas são portadores de uma mutação $271 \mathrm{C} \Rightarrow$ $\mathrm{T}$, e outra mutação $304 \mathrm{G} \Rightarrow \mathrm{A}$. Ambas mutações foram identificadas entre os negros brasileiros. A mutação $304 \mathrm{G} \Rightarrow \mathrm{A}$, que codifica para $\mathrm{Ala} \Rightarrow \mathrm{Thr}$, no resíduo 120 de aminoácidos, é uma mutação polimórfica ( $N$ eote et al., 1994). De acordo com a estrutura tridimensional do produto do gene Duffy, proposta por H adley \& Peiper (1997), que envolve sete segmentos transmembranares, 0 aminoácido 102 estaria no segundo segmento transmembranar, e a substituição $\mathrm{Ala} \Rightarrow \mathrm{Thr}$ poderia levar apenas a uma modesta mudança na propriedade dos receptores. A mutação $271 \mathrm{C} \Rightarrow T$, por outro lado, converte o resíduo 91 , possivelmente situado no primeiro loop citoplasmático, de $\mathrm{Arg} \Rightarrow \mathrm{Cys}$, 0 que representa uma mudança considerável na natureza química da região. Isto pode afetar 0 comportamento do receptor Duffy e seus sítios antigênicos extracelulares. H ouve discrepância entre os fenótipos (nulo) e genótipo ( $\left.\mathrm{F} Y{ }^{*} \mathrm{~B}\right)$, sugerindo uma associação com o gene silencioso $F Y^{*} B$ nas células eritrocitárias. 0 fenótipo nulo inicial mente estava associado apenas ao alelo FY*B. Zimmerman et al. (1999) descreveram a mesma transição ( $46 \mathrm{~T} \Rightarrow \mathrm{C}$ ) no GATA box associada ao alelo $\mathrm{FY} * \mathrm{~A}$, mutação que leva a fenótipo nulo ( $F Y^{*} A$ nulo), numa população de Papua, N ova Guiné, sugerindo que a emergência do al el o $\mathrm{FY}^{*} A$ nulo nesta população está envolvida com sel eção do polimorfismo eritrocitário: ao contrário da fixação do alelo FY*Bnulo, na ausência de $P$. vivax na África ocidental, a aparente recente emergên cia do $F Y^{*} A$ nulo naquela população da Nova Guiné cria a oportunidade de se estudar o significado desta mutação para a suscetibilidade à infecção à malária e à morbidade clínica. Está bem demonstrado que D uffy-negativo explica claramente resistência a merozoítas de $P$. vivax, mas pouco se conhece a respeito dos fatores que contribuíram para a fixação do alelo B-nulo em populações africanas etnicamente diversas. Livingstone (1984) discutiu o aparente paradoxo sobre a existência de alta freqüência do alelo $\mathrm{FY} * \mathrm{~B}$ nulo (às vezes atingindo $100 \%$, em al gumas populações) em áreas em que não existe malária vivax. Foram propostas al gumas hipóteses e a mais provável éa adaptação do $P$. vivax a climas temperados e à alta freqüência preexistente do alelo nulo, impedindo que a malária vivax se tornasse endêmica na África ocidental. H amblin \& Di Rienzo (2000) centraram seus estudos numa população subsaariana da África, em que o alelo nulo está virtualmente fixado, analisan- do a variação existente ao redor da mutação na região promotora GATA. Para suas análises, assumiram que a própria mutação $\mathrm{FY} * 0$ foi 0 alvo da seleção, e não um gene vizinho a ele. 0 valor $\mathrm{F}(\mathrm{ST})$ de Wright para 0 alelo $\mathrm{FY} \mathrm{F}^{*} 0$ é 0 mais alto de qualquer polimorfismo humano (Cavalli-Sforza et al., 1994), o que é uma evidência de seleção no loco FY. Para caracterizar a ação (assinatura) de seleção direcional neste loco, $\mathrm{H}$ amblin \& Di Rienzo escanearam a variação de seqüência de $D N A$, tanto na região $1,9 \mathrm{~kb}$ centrada no sítio da mutação $\mathrm{FY} * \mathrm{O}$, como nas regiões de $1 \mathrm{~kb}$ a 5-6 kb distantes do sítio, em 17 italianos ( 34 cromossomos) e 24 indivíduos ( 48 cromossomos) de cinco regiões subsaarianas da África. Ainda que a variabilidade encontrada na população africana apresentasse ao redor de $50 \%$ mais diversidade genética do que a encontrada em europeus, a região D uffy foi 2-3 vezes mais variável nos italianos que nos africanos. Como um todo, a população africana desviou-se significantemente do esperado por ação neutra na fixação do gene. $M$ as os autores não puderam identificar se esse fato foi devido à recombinação, mutação recorrente, estrutura da população, e/ ou acúmulo de mutação, e deriva. M esmo não sendo possível distinguir entre essas hipóteses alternativas, concluiu-se que, provavelmente, os dois maiores haplótipos ocorridos em 3 das 5 populações africanas, e que continham o alelo nulo, originaram-se antes da operação da seleção na mutação $\mathrm{FY}^{*}$ nulo. Alguns brancos expressam quantidades reduzidas ou fracas de Fyb (H adley \& Peiper, 1997, para revisão), cujas bases genéticas ainda são incertas.

DARC - Eritrócitos que apresentam o fenótipo Duffy nulo não são capazes de se ligar a Interleucin-8 (IL-8). Evidências experimentais, como: 1 - ligação mínima ou nula de IL-8 a eritrócitos Duffy negativo; 2 - um anticorpo monoclonal ao antígeno do grupo sangüíneo Duffy bloqueando a ligação de IL-8 e outras quimiocinas a eritrócitos Duffy positivo, levaram H oruk et al. (1993) a identificar a gpFy como um receptor de quimiocina, passando o loco a se chamar Antígeno D uffy para Receptor de Quimiociona (DARC, em inglês). Invasão celular pelo parasita consiste de múltiplos passos, que incluem reconhecimento, reorientação para deixar o fim apical do parasita em contacto com o eritrócito, uma junção parasita/hospedeiro e a entrada no vacúolo criado pelo parasita. Há muitos receptores envolvidos nestes estágios. GP Duffy é um receptor promíscuo, 
uma vez que se liga não só ao $P$. vivax, mas também a várias quimiocinas tanto do grupo C-C (RANTES, M CP-1) como C-X-C (IL-8, M GSA/gro) (N eote et al., 1994). I sto é uma indicação de que existem outras funções para a glicoproteína Duffy, que não meramente evitar a invasão pelo P. vivax. $O$ papel fisiológico preciso deste receptor, tanto em condições normais como patológicas, ainda é incerto. A proteína Duffy não se encontra exclusivamente nos eritrócitos, sendo também encontrada nos rins, baço efígado fetal (Chaudhuri et al., 1995). Em P. vivax, o ligante merozoíta que interage com DARC foi identificado como a Duffy binding protein (DBP), por W ertheimer $\&$ Barnwell (1989). É uma proteína de 140kD codificada por uma cópia simples de gene. Análises experimentais demonstraram que DBP, um peptídeo de 34 aminoácidos, apresenta um domínio extracelular rico em cisteína ( região II), que éa região do parasita que se liga ao antígeno do grupo sangüíneo Duffy no eritrócito humano (Chitnis \& M iller, 1994). Análises moleculares indicaram que as proteínas de ligação dos parasitas $P$. knowlesi, $P$. vivax e P. falciparum possuem regiões de homologia (Adams et al., 1992). Os merozoítas de $P$. vivax invadem preferencialmente os reticulócitos, através de receptores que não foram ainda caracterizados (ver Wertheimer \&Barnwell, 1989, para revisão).

\section{Genética molecular funcional de Plasmodium}

Os estudos de genética molecular de plasmódios datam do início da década de 1980, quando a equipe da $\mathrm{New}$ York U niversity $\mathrm{M} \mathrm{e}$ dical School conseguiu, pela primeira vez, clonar e expressar seqüências gênicas correspondendo à proteína Circum-Sporozoita (CSP), identificada como tendo capacidade vacinal em malária (Nussenzweig \& N ussenzweig, 1989). A partir dos anos 1980, numerosos laboratórios desenvolveram pesquisas de clonagem molecular de genes codificando diferentes antígenos. Em 1995 foram desenvolvidas técnicas de transformação estável de parasitas de malária de roedores (van Dijk et al., 1995), estendidas em seguida a Plasmodium falciparum (Crabb \& Cowman, 1996; Wu et al., 1996). U sam-se plasmídeos "navete" contendo promotores bacterianos e do parasita, com seqüências gênicas de plasmódio e marcadores que permitem identificar os parasitas transfectados por eletroporação. Servem como marcadores selecionáveis o gene de dihidrofolato redutase com mutação de resistência ao antifólico WR99210 (Fidock $\&$ W ellems, 1997) ou o gene da puromicina- $N$ acetil transferase que confere resistência à puromicina (de Koning et al., 2001). Com tais vetores, tem-se obtido a transformação estável de parasitas para estudos funcionais por inativação (knock out) de genes, por substituição de parte ou totalidade de genes parasitários (recombinação homóloga) e por testes de complementação. A partir de 1995, por iniciativa da fundação W ellcome, foi desenvolvido um programa de clonagem do genoma completo dos 14 cromossomos de Plasmodium falciparum envolvendo vários laboratórios europeus e americanos. Seqüências completas dos cromossomos 2 e 3 (Gardner et al., 1998; Bowman et al., 1999) foram já publicadas e espera-se para 0 fim do corrente ano a publicação da seqüência completa do genoma de P. falciparum. Pode-se já consultar databank no sítio web de David Roos (http://www. plasmodb.org) no que se refere ao total de EST (expressed sequence tags) identificados. Passaremos assim, em relação a $P$. falciparum a uma fase que pode ser qual ificada de pós-genômica, em que os pesquisadores se dedicarão a identificar funções dos diferentes genes já seqüenciados. Plasmodium vivax, que pela sua área de incidência interessa principalmente à América do Sul eáreas do Pacifico, provoca infecção menos grave, raramente mortal e tem merecido menores investimentos de pesquisa (del Portillo et al., 2001). Pesquisas sobre genômica funcional têm-se concentrado particularmente em P. falciparum e nas seguintes áreas: 1) análises funcionais de genes codificando antígenos candidatos a vacinas; 2 ) análises de genes responsáveis pela resistência a drogas; 3) estudos de genes relacionados com a patogênia de plasmódios e mecanismos de escape às reações imunes.

\section{Análise funcional de genes codificando antígenos candidatos a vacinas}

Não é objetivo do presente trabal ho rever a abundante literatura sobre vacinas antimaláricas que podem ser encontradas em excelentes revisões recentes (Engers \& Godal, 1998; H older et al., 1999; Doolan \& H offmann, 2001). Iremos aqui apenas selecionar al guns exemplos de estudos funcionais sobre as proteínas antigênicas. Assim, a equipe da N ew York University, usando parasitas de roedor, obteve a inativação do gene codificando a proteína CSP (cir- 
cum sporozoita) e a do gene codificando a proteína TRAP (trombospondin related antigen protein), ambas identificadas como proteínas da membrana dos esporozoïtas e propostas como bases de vacinas. $A$ inativação do gene da CSP não perturbou o desenvolvimento do ciclo sexuado até a formação do oocisto no tubo digestivo do anofelino, mas demonstrou que 0 gene é essencial para a morfogenese de esporozoïtas. A inativação do gene trap, ao contrário, não afetou a morfogênese do esporozoïta, mas alterou profundamente sua motilidade, e os esporozoïtas mutantes mostraram-se incapazes de penetrar a glândula salivar do anofelino (N ussenzweig et al., 1997; 2001).

Os mecanismos de adesão e penetração dos merozoïtas nos glóbulos vermel hos vêm sendo estudados em uma série de trabal hos. Entre as diversas proteínas que foram relacionadas com esses processos e propostas como candidatos vacinais estão as proteínas M SP ( M erozoïta surface protein 1, 2 e 3) em P. falciparum (revisão em Holder et al., 2000) e a M SP-1 em P. vivax (Perera et al., 1998). Experiências de transfecção com objetivo de inativar o gene M SP 1 de $P$. falciparum indicam que este gene é essencial, assim como outra proteína relacionada com a invasão, 0 antígeno AM A (apical membrane antigen). Experiências da equipe australiana mostraram a possibilidade de substituir 0 gene ama de P. falciparum pelo correspondente de P. chabaudi, resultando em parasitas com capacidade complementada a 30\% para a invasão de glóbulos humanos e eficiente capacidade de invasão de glóbulos vermelhos de camundongo (Triglia et al., 2000).

I gualmente essenciais parecem ser as funções de proteases intervindo na fase de penetração dos merozoïtas. Duas proteases identificadas por Blackman e colaboradores são responsáveis pelo processamento do precursor pro AM A de $83 \mathrm{kD}$ a nas organelas secretoras do merozoïta em duas etapas aos produtos finais solúveis de 44 e $48 \mathrm{kDa}$ (H owell et al., 2001). Outra protease, de tipo subtilisina, descrito em P. falciparum, parece ser essencial, pois a inativação do gene correspondente de $P$. berghei tem efeito letal para o parasita. Essa protease é associada ao processamento final do antígeno M SP-1 (Barale et al., 1999) originando o segmento C-terminal de $19 \mathrm{kD}$ a ancorado ao merozoïta. 0 segmento $19 \mathrm{kD}$ a da proteína M SP-1 é considerado candidato vacinal.

Outra proteína vacinal interessante que vem sendo estudada é o antígeno EBA-175 (erythocyte binding protein), que participa de contato inicial do merozoïta com o eritrócito, ligando-se ao ácido siálico da glicoforina A. A inativação do gene eba- 175 conduziu a resultados inesperados: quando as regiões mediana ou C-terminal citoplasmática da proteína são truncadas, a invasão de glóbulos vermelhos pelos merozoïtas mutantes não é afetada. Entretanto, 0 truncamento da região $\mathrm{N}$ terminal, exposta na superfície, abole a capacidade de invadir eritrócitos mas, paradoxalmente, desenvolve uma nova capacidade, a de invadir glóbulos vermelhos tratados por neuraminidase que elimina os radicais siálico da glicoforina. 0 mutante apresenta uma comutação(switch) para uma nova via de invasão de glóbulos vermeIhos independente de ácido siálico (Reed et al., 2000). Estudos recentes da equipe de Cowman (Thompson et al., 2001) identificaram um gene codificando uma proteína - EBA-140 - homóloga de EBA-175 e ligando-se igualmente a receptor contendo ácido siálico. Esses resultados, e outros de inativação de genes da família msp, indicam um enorme potencial do parasita para expressar vias alternativas de penetração do merozoïta, o que lhe garante grande vantagem para sobreviver à pressão dos fatores imunitários e à heterogeneidade de receptores do hospedeiro. A multiplicidade de vias alternativas não é restrita às funções do merozoïta. Também se apresenta em funções relacionadas com o ciclo sexuado no mosquito. Assim parece suceder com as proteínas P25 e P28 do oocineto, ambas descritas como candidatas à vacina "de bloqueio de transmissão". Experiências promovendo a inativação de um ou de ambos os genes codificando esses antígenos mostraram que a penetração do oocineto na parede do tubo digestivo do mosquito e sua transformação em oocisto é apenas parcialmente inibida quando um dos genes éinativado, sendo inibida de modo significativo apenas quando ambos os genes são inativados (Tomas et al., 2001).

\section{Genômica funcional da resistência de Plasmodium falciparum a drogas}

A tremenda capacidade de adaptação dos parasitas da malária, graças à plasticidade de seu genoma, evidencia-se na rapidez com que se desenvolveu, em particular em P. falciparum, resistência a praticamente todos os antimaláricos sintéticos desenvolvidos a partir dos anos 1940, quando as 4 e 8 aminoquinoleínas foram introduzidas, assim como as sulfonamidas, os 
antifólicos do tipo pirimetamina e o proguanil. Os estudos moleculares permitiram esclarecer rapidamente a natureza das mutações, provocando a resistência a antifólicos e sulfonamidas, e afetando os genes da dihidrofolato redutase (DHFR) e da dihidro pteroato sintase (DHPS) (Cowman et al., 1988). Estudos detaIhados nesse sentido foram desenvolvidos em várias áreas da Amazônia brasileira (Vasconcelos et al., 2000; Vieira et al., 2001), confirmando os resultados de Cowman et al. (1988).

A resistência à cloroquina de Plasmodium falci parum, inicialmente observada nos anos 1960 na América do Sul e na Ásia do sudeste, estende-se hoje por todas as regiões endêmicas de Plasmodium falciparum nos três continentes e foi assinalada em relação a Plasmodium vivax em al gumas regiões da Ásia (Wellems \& Plowe, 2001).

A identificação de funções genéticas relacionadas com a resistência à cloroquina avançaram nos últimos anos em duas direções: as primeiras correlações estabelecidas indicaram a presença de mutações nos genes mdr (multidrug-resistance). Os genes mdr de P. falciparum - pfmdr1 e pfmdr2 foram identificados por homologia com os genes mdr em células tumorais multirresistentes a drogas por mecanismos de efluxo acelerado. Resultados preliminares identificaram a glicoproteína Pgh-1, codificada por pfmdr1 como moduladora de absorção-secreção da cloroquina em culturas de parasita in vitro (Cowman et al., 1991). Alguns estudos de terreno indicaram uma correlação entre certos polimorfismos de pfmdr1 e resistência à cloroquina (Foote et al., 1990; Nagesha et al., 2001), mas vários outros não mostraram tal correlação. Dúvidas persistem, portanto, sobre o papel de mutações de mdr na resistência de P. falciparum à cloroquina.

Outra série de estudos conduzidos pela equipe de W ellems, do National Institute of $\mathrm{H}$ ealth, desenvolveu-se em direção diferente: em uma el egante experiência, a equipe realizou um cruzamento, de duas cepas clonais de P. falciparum, uma resistente e outra sensível à cloroquina. Fragmentos RFLP codificando 85 proteínas do parasita foram usados como marcadores. Os mosquitos alimentados com as duas cepas infectaram um chimpanzé e deste foram isolados 16 linhagens clonais de P. falci parum, 8 cloroquina sensíveis e 8 resistentes. A análise da distribuição dos marcadores revelou que 0 fenótipo sensível/resistente é regulado por um único locus de 400 kb no cromossoma 7 (Wel- lems et al., 1991). A utilização de outros marcadores permitiu em seguida reduzir o segmento do locus a $40 \mathrm{~kb}$ que, seqüenciado, identificou o gene Pfcrt como sendo associado à resistência à cloroquina (Fidock et al., 2000). U m extenso trabalho de seqüenciamento de genes Pfcrt de isolados de parasitas naturais de quatro continentes permitiu identificar 10 mutações pontuais associadas ao fenótipo resistente. Entretanto, apenas a mutação no codon 76 , com substituição de Lisina (AAA/AAG) por treonina $(A C X)$ mostrou correlação constante com o fenótipo resistente. Além disso só se observou a mutação K 76T em isolados com outros dos 9 códons afetados por mutações (Wellems \& Plowe, 2001). Estudos na região amazônica confirmam inteiramente a correlação entre a mutação $\mathrm{K} 76 \mathrm{~T}$ e a resistência à cloroquina (Vieira et al., 2001). Por outro lado, estudos realizados sobre os genes homólogos a pfcqr em isolados de Plasmodium vivax resistentes à cloroquina não mostraram nenhuma associação entre resistência à cloroquina in vivo e mutações no gene de P. vivax (Nomura et al., 2001). Isso indicaria mecanismos diferentes de resistência.

\section{Estudos de genética funcional da virulência de Plasmodium falciparum}

Plasmodium falciparum éa espécie mais virulenta de malária, responsável por formas graves, levando com freqüência a óbito. Na África, essas formas graves manifestam-se principalmente sob três formas: malária cerebral em crianças, anemia grave em crianças e adultos jovens, e malária da gestante. Pesquisas realizadas em dois laboratórios americanos (NIH e Affymax) e um inglês (M olecular M edicine, Oxford) levaram em 1995 à descoberta dos genes responsáveis pela variação antigênica e pela seqüestração de Plasmodium falciparum - os genes var - (revisões em N ewbold et al., 1999; N ogueira et al., 2001; Craig \& Scherf, 2001). Os genes var constituem uma família poligênica de 40 a 50 elementos, distribuídos nos 14 cromossomos do parasita, que codificam as proteínas PfEM P-1 (erythrocyte membrane protein n.1), expostas na superfície do glóbulo vermelho parasitado e responsáveis pela seqüestração de formas evolutivas dos parasitas por adesão e retenção dos mesmos nos capilares pós-venosos. Quando a seqüestração ocorreintensamente em órgãos nobres como o cérebro, o pulmão, o rim ou a placenta, desenvolvem-se patologias graves, sendo particularmente grave 
a seqüestração no cérebro, causando malária cerebral. Dois fenômenos de interação dos glóbulos parasitados com estruturas celulares do hospedeiro humano foram identificados na seqüestração: a citoaderência e a formação de rosetas. Ambos os fenômenos dependem da proteína PfEM P-1 e a análise dos genes var mostrou a estrutura peculiar dessas proteínas. São proteínas de alto peso molecular (200 a 300 $\mathrm{kD}$ a) integradas à membrana do glóbulo parasitado. São extremamente polimórficas, mas guardam certas características comuns, apresentando vários motivos homólogos a proteínas denominadas "Duffy binding proteins" de $P$. vivax e denominados motivos "Duffy binding like" - DBL.

A citoaderência dos glóbulos vermelhos infectados com formas maduras do parasita (trofozoitas e esquizontes) faz-se por interação de motivos DBL da proteína PfEM P-1 com receptores endoteliais, que nada mais são do que adesinas e integrinas, responsáveis por captação de glóbulos brancos nos processos de diapedese da corrente sangüínea para os tecidos. Os receptores bem identificados são ICAM - 1 (inter cellular adhesion molecule-1), VCAM (vascular cell adhesion molecule), CD36, CD 31 entre outros. Os parasitas adaptaram-se portanto a reconhecer receptores preexistentes para realizar a citoaderência, que representa, para eles, um meio de evitar a passagem pelo baço, onde al terações da membrana celular dos eritrócitos provocaria sua captura e destruição por células fagocitárias. Pesquisas de vários grupos permitiram identificar a região da molécula PfEM P-1 responsável pela especifidade de adesão a um ou outro receptor. Assim, a citoaderência responsável pela seqüestração no cérebro foi identificada como dependendo dos receptores ICAM - 1 e dos motivos D BL-b associados ao interdomínio próximo (Smith et al., 2000). A forma grave de malária de gestante é resultante da citoaderência de certas PfEM P-1 contendo motivo particular de DBL-g que reconhece como receptor radicais CSA (condroitin sulfato A) de certas glicoproteínas abundantes na placenta (Buffet et al., 1999). Portanto, a virulência particular de certas infecções de malária falcípara se explicaria, atualmente, pela associação de fatores do hospedeiro humano e do parasita: a expressão induzida de receptores regulados por certas citocinas de um lado e a expressão de certos genes var do parasita de outro (Craig \& Scherf, 2001). 0 outro fenômeno que participa da seqüestração é a formação de rosetas, pela qual glóbulos vermelhos nãoparasitados aderem aos glóbulos vermelhos parasitados formando grumos celulares capazes de perturbar a circulação capilar. Certas proteínas PfEM P1, através do motivo DBL-a, reconhecem receptores na superfície dos eritrócitos sãos que podem ser o fator grupo sangüíneo A, o receptor do complemento (CR1) e CD 36 (Chen et al., 1998). Segundo U domsangpetch et al. (1993), a maior suscetibilidade à infecção por P. falciparum, em indivíduos portadores do grupo sangüíneo $A$, do sistema $A B O$, deve-se a uma taxa de rosetas mais alta que estes indivíduos apresentam.

Registre-se finalmente que foram descritas recentemente famílias poligênicas em Plasmodium vivax codificando antígenos variantes com centenas de membros (del Portillo et al., 2001). 0 significado e funções destes antígenos estão sendo estudados.

\section{Estudos de genômica funcional de vetores anofelinos}

Os anofelinos são vetores obrigatórios da malária humana e no interior deles se processa o ciclo sexuado dos plasmódios: amadurecimento dos gametas, fusão e formação do zigoto e do oocineto que atravessa a parede do intestino médio e se transforma em oocisto, onde se formam os esporozoïtas, que, após ruptura do oocisto, se dirigem para as glândulas sal ivares, onde penetram ativamente. A especificidade de relações parasita-mosquito é demonstrada pela existência de anofelinos sensíveis e refratários a infecção por plasmódios. M esmo em laboratório foram obtidos mutantes refratários de Anophel es gambiae, enquanto o tipo selvagem da espécie é o melhor vetor conhecido de malária (Brey et al., 1995). Cada uma das etapas do ciclo evolutivo depende de interações específicas entre estruturas moleculares do parasita e do hospedeiro mosquito. Em particular, o oocineto deve atravessar a membrana peritrófica e o epitélio do intestino médio, enquanto os esporozoïtas devem atravessar o epitélio das glândulas salivares. Resulta dessas interações a maior ou menor capacidade vetorial de cada anofelino por cada espécie de Plasmodium. Assim os esporozoïtas de P. knowlei invadem as glândulas salivares de Anopheles dirus, mas não as de A. freeborni. Em estudo comparativo de Klein e colaboradores (1991) com seis vetores de P. falciparum na Amazônia brasileira, verificou-se que, em relação à competência 
vetorial, A. darlingi eA. mediopunctatus se equivalem e foram superiores em ordem decrescente a deanorum, triannulatus e oswaldoi. Em A. albitarsis, observou-se a formação de oocistos mas os esporozoïtas foram incapazes de invadir as glândulas salivares (Klein et al., 1991). Em estudos recentes, comparando a capacidade vetorial de A. albimanuse A. pseudopunctipennis pelo $P$. vivax, observou-se que o primeiro é refratário a P. vivax de fenotipo VK247 e sensível a P. vivax VK210 enquanto o segundo mostra refratoriedade inversa ( $G$ onzales Ceron et al., 2001). Em anofelinos refratários da espécie A. gambiae, foi estudada em laboratório a trajetória dos oocinetos formados após ingestão de sangue com gametócitos e observou-se que eles são destruídos e encapsulados por estruturas ricas em melanina. Fenol oxidases de tipo tirosina foram identificados em vários insetos e nos an ofelinos refratários como implicados na mielinização e, em estudos recentes, mostrou-se que a regulação do gene da profenoloxidase 1 é regulado pelo hormônio ecdisona (Ahmed et al., 1999). A fenoloxidase se conta portanto entre os fatores imunes do mosquito cuja natureza vem recentemente sendo estudada por grande número de pesquisadores. 0 objetivo a termo desses estudos é a de produzir mutantes refratários das espécies vetoras de malária, capazes, num segundo tempo, de substituir as populações naturais através do fluxo genético entre populações. Assim, desenvolve-se atualmente um programa internacional de seqüenciamento do genoma de Anopheles gambiae. Por outro lado, desenvolvem-se pesquisas para identificar os atores do sistema imune do mosquito relacionados com a refratoriedade. Vários peptídeos com atividade antibacteriana e antiplasmodial têm sido identificados (Vizioli et al., 2001). U m estudo sistemático através de um projeto piloto para identificação de genes é desenvolvido atualmente pela equipe de Kafatos no Laboratório Europeu de Biologia M olecular (Dimopoulos et al., 2000). N esse projeto acumulam-se seqüências gênicas expressas no tubo digestivo de mosquito e constróem-se bancos de DNA. Os EST (expressed sequence tags) são analisados em mosquitos controles e mosquitos infectados com bactérias e parasitas da malária para definir seqüências relacionadas com fatores imunitários. Foram assim identificadas até 0 momento 19 seqüências relacionadas com respostas imunes e el as se encontram em fase de análise. Parecem codificar peptídeos, em geral. Em outra série de estudos, uma biblioteca de phage display foi utilizada para identificar receptores do oocineto no intestino médio e de esporozoïtas nas glândulas salivares. I dentificou-se assim um peptídeo de 12 ácidos aminados que interage com a superfície do epitélio do intestino médio e com o lobo distal das glândulas salivares eque, ao mesmo tempo, inibe a invasão das glândulas salivares por esporozoïtas (Ghosh et al., 2001). A interação do peptídeo parece pois definir sítios de interação do parasita e pode ser útil na modificação genética da capacidade vetorial.

U ma via inteiramente diferente vem sendo seguida pelo grupo da Universidade da Califórnia em Irvine. $O$ projeto consiste na produção de mosquitos transgênicos secretando no aparelho digestivo fatores introduzidos por engenharia genética que inibam o desenvolvimento do parasita. Experiências engenhosas foram realizadas no modelo Aedes - Plasmodium galinaceum com introdução, sob controle, de promotor de mosquito, do gene codificando para cadeias variáveis de anticorpo monoclonal antiproteína CSP (ciscumsporozoita) de P. galinaceum. Os resultados dessas experiências são promissoras pois o nível de inibição da colonização da glândula salivar do mosquito transgê nico, por esporozoïtas, foi considerável (James et al., 1999; Capurro et al., 2000). 


\section{Referências bibliográficas}

Adams JH et al. 1992. A family of erythrocyte binding proteins of malaria parasites. Proc. Natl. Acad. Sci. USA; 89:7.085-7.089.

Ahmed A et al. 1999. Genomic structure and ecdysone regulation of the prophenoxidase 1 gene in the malaria vector Anopheles gambiae. Proc. N atl. Acad. Sci. USA 96 (26):14.795-14.800.

Allison AC 1954. Protection afforded by sickle-cell trait against subtertian malarial infection. Biochemical Genetics:153-163.

Ashley-Koch A, Yang Q \& Olney RS 2000. Sickle hemoglobin ( $\mathrm{Hb}$ S) allele and sickle cell disease: a huge review. Amer. J. Epidem. 51 (9):839-845.

Barale JC et al. 1999. Plasmodium falciparum subtilisinlike protease 2, a merozoïte candidate for the merozoïte surface protein 1-42 maturase. Proc. N atl. Acad. Sci. USA 96(11):6.445-6.450.

Bowman S et al. 1999. The complete nucleotide sequence of chromosome 3 of Plasmodium falciparum. Nature 400:532-538

Brey PT et al. 1995. Tyrosinase-type prophenoloxidase distribution in the alimentary canal of strains of Anopheles gambiae refractory and susceptible to Plasmodium infection. Exp. Parasitol .80(4):654-664.

Buffet PA et al., 1999. Plasmodium falciparum domain mediating adhesion to chondroitin sulfate $A$ : a receptor for human placenta infection. Proc. $\mathrm{N}$ atl. Acad. Sci. USA 96:5.198-5.202.

Cappadoro M et al. 1992. Early phagocytosis of glucose6-phosphate dehydrogenase (G6Pd)- deficient erythrocytes parasitized by Plasmodium falciparum may explain malaria protection in G6PD deficiency. Blood 92(7):2.527-2.534.

Capurro ML et al. 2000. Virus expressed recombinant single-chain antibody blocks sporozoïte infection of salivary glands in Plasmodium gallinaceum infected Aedes aegypti. Am. J. Trop. M ed. Hyg. 62:427-433

Cavalli-Sforza LL, M enozzi P \& Piazza A 1994. The history and geography of human genes. Princeton University Press, Princeton, NJ.

Chaudhuri A, Polyakova J, Zbrzezna V \& Pogo AO 1995. The coding sequence of Duffy blood group gene in humans and simias: restriction fragment length polymorphism, antibody and malarial parasite specificities, and expression in nonerythroid tissues in Duffy-negative individuals. Blood 85(3).

Chen Q et al. 1998. Identification of Plasmodium falciparum erythrocyte membrane protein 1 (PfEM P1) as the rosetting ligand of the parasite $P$. falciparum. J. Exp. M ed. 187:15-23.

Chitnis CE \& Miller LH 1994. Identification of the erythrocyte binding domains of Plasmodium vivax and Plasmodium knowlesi protein involved in erythrocyte invasion. J. Exp. M ed. Aug. 1; 180 (2):497-506.

Cowman AF, Karcz S, Galatis D \& Culvenorm JG 1991. A P-glycoprotein homologue of Plasmodium falciparum is localized on the digestive vacuole. J. Cell. Biol. 113:1.033-1.045.

Cowman AF et al. 1988. Amino acid changes linked to pyrimethamine resistance in the dihydrofolate reductase-thymidylate synthase gene of. Plasmodium falciparum. Proc. Natl. Acad. Sci. USA 85(23):9.1099.113.
Crabb BS \& Cowman AF 1996. Characterization of promoters and stable transfection by homologous and nonhomologous recombination in Plasmodium falciparum. Proc. Natl. Acad. Sci. USA 93(14):7.2897.294

Craig A \& Scherf A 2001. M olecules on the surface of the Plasmodium falciparum infected erythrocyte and their role in malaria pathogenesis and immune evasion. M ol. Biochem. Parasitol. 115:129-143.

Cutbush M, M ollison PL \& Parkin DM 1950. A new human blood group. Nature 165:188.

de Koning-Ward TF, Waters AP \& Crabb BS 2001. Puromycin- $\mathrm{N}$-acetyltransferase as a selectable marker for Plasmodium falciparum. M ol. Biochem. Parasitol. 117(2):155-160.

de Oliveira $\mathrm{Cl}$, Wunderlich $\mathrm{G}$, Levitus $\mathrm{G}$ et al. 1999. Antigenic properties of the merozoite surface protein 1 gene of Plasmodium vivax. Vaccine 17(23-24):2.9592.968.

Deane LM 1992. Os grandes marcos na história do controle da malária no Brasil. Rev. Soc. Brasil M ed. Trop. 25(supl II): 12-22.

Deane LM 1988. M alaria studies and control in Brazil. Am. J. Trop. M ed. Hyg. 38: 223-230.

del Portillo HA et al. 2001. A superfamily of variant genes encoded in the subtelomeric region of Plasmodium vivax. N ature 410: 839-842.

Destro-Bisol G, D'Áloja E, Spedini G, Scatena R, Giardina B \& Pascali V 1999a. Brief communication: resistance to Falciparum malaria in a-Thalassemia, oxidative stress, and hemoglobin oxidation. Am. J. Phys. Anthrop. 109: 269-273.

Destro-Bisol G, Vienna A, Battaggia C, Paoli G \& Spedini $G$ 1999b. Testing a biochemical model of human genetic resistance to Falciparum malaria by the analysis of variation at protein and microsatellite loci. Hum. Biol. 71(3):315-332.

Dimopoulos G et al. 2000. Anopheles gambiae pilot gene discovery project: identification of mosquito innate immunity genes from expressed sequence tags generated from immune competent cell lines. Proc. $\mathrm{N}$ atl. Acad. Sci. USA 97(12): 6.619-6.624

Donahue RP, Bias WB, Renwick JH \& M cKusick VA 1968. Probable assignment of the Duffy blood group locus to chromosome 1 in man. Proc. Natl. Acad. Sci . USA 61:949-955.

Doolan DL \& H offmann SL 2001. DNA-based vaccines against malaria: status and promise of the multistage malaria DN A vaccine operation. Int. J. Parasitol. 31(8):753-762.

Engers HD \& Godal T 1998. M alaria vaccine development. Parasitol. Today 14:56-60.

Feitosa M F et al. 2001. A major genetic mechanism involved in resistance to malaria in Western Amazonia. Genetic Epidemilogy, submetido.

Fidock DA et al. 2000. M utations in the P. Falciparum digestive vacuole transmembrane protein PfCRT and evidence for their role in chloroquine resistance. Mol. Cell. 6(4):861-871.

Fidock D \& W ellems T 1997. Transformation with human dihidrofolate reductase renders malaria parasites sensitive to WR99210 but does not affect the intrinsic activity of proguanil. Proc. Natl. Acad. Sci. 
(USA) 94(20):10.931-10.9366.

Foote SJ et al. 1990. Several alleles of the multidrug-resistance gene are closely linked to chloroquine resistance in Plasmodium falciparum. Nature 345:202203.

Funasa 2000. Fundação Nacional de Saúde. Plano de intensificação das ações de controle de malária nos estados da Amazônia Legal, 73p (mimeo).

Gardner MJ, Tettlin H, Carucci GJ et al. 1998 Chromosome 2 sequence of the human malaria parasite Plasmodium falciparum. Science 282:1.126-1.132.

Garrod AE 1931. The inborn factors in disease. An essay. Oxford University Press, Oxford, UK.

Ghosh AK, Ribolla PE \& J cobs-Lorna M 2001. Targeting Plasmodium ligands on mosquito salivary glands and midgut with a phage display peptide library. Proc. Natl. Acad. Sci. USA 98(23):13.278-13.281.

Gonzales Ceron L et al. 2001. Plasmodium vivax: ookynet destruction and oocyst development arrest are responsible for Anopheles albimanus resistance to circum sporozoïte phenotype VK247 parasites. Exp. Parasitol. 98(3):152-161.

Hadley TJ \& Peiper SC 1997. From malaria to chemokine recptor: the emerging physiologic role of the Duffy bBlood group antigen. Blood 89(9):3.077-3.091.

$\mathrm{H}$ aldane JBS 1948. The rate of mutations of human genes. Proceedings of the Eighth International Congress of Genetics and Heredity. H ereditas Suppl. 35.

$\mathrm{H}$ amblin M T \& Di Rienzo A 2000. Detection of the signature of natural selection in humans: evidence from the Duffy blood group locus. Am. J. Hum. Genet. 66:1.669-1.679.

Hill AVS et al. 1991. Commom West African HLA antigens are associated with protection from severe malaria. N ature 352:595-600.

Hill AVS et al. 1992. M olecular analysis of the association of HLA-B53 and resistance to severe malaria. Nature 360:434-439.

Holder AA et al. 1999. M erozoite surface protein 1, immune evasion and vaccines against asexual blood stage malaria. Parassitologia 41(1-3):409-414

Horuk $\mathrm{R}$ et al. 1993. A receptor for a malarial parasite Plasmodium vivax: the eythrocyte chemokine receptor. Science 261(5.125):1.182-1.184.

H owell AS et al., 2001. Proteolytic processing and primary structure of Plasmodium falciparum apical membrane antigen-1. J. Bio. Chem. 276(33):31.311-31.320.

Ikin EW, M ourant AE, Pettenkoffer JH \& Blumenthal G 1951. Discovery of the expected haemagglutinim anti-Fyb. Nature 168:1.077.

James AA et al. 1999. Controlling malaria transmission with genetically-engineered Plasmodium-resistant mosquitoes: milestones in a model system. Parassitologia 41(1-3):461-471.

Klein TA, Lima JBP \& Tada MS 1991. Comparative susceptibility of anopheline mosquitoes to Plasmodium falciparum in Rondônia, Brazil. Am. J. Trop. Med. Hyg. 44(6):598-603.

Livingstone FB 1984. The Duffy blood groups, vivax malaria and malaria selection in human populations: a review. Hum. Bio. 56(3):413-425.

Luzzatto L \& N otaro R 2001. Protecting against bad air. Science 293:442-443.

M allinson G, Soo KS, Schall TJ, Pisacka M \& Anstee DJ 1995. M utations in the erythrocyte chemokine recptor (D uffy) gene: the molecular basis of the Fya/Fyb antigens and identificatio of a deletion in the Duffy gene of an apparently healthy individual with the Fy (a-b-) phenotype. Br. J. Haematol. 90:823-829.

$M$ arques AC 1987. Human migration and the spread of malaria in Brazil. Parasitol. Today 3:166-170.

M arques AC e Gutierrez HC 1993. Combate à malária no Brasil: evolução, situação atual e perspectivas. In Trajetória de um sanitarista, OPAS/OMS, Representação do Brasil editores, Brasília, pp. 38-67.

M cAlpine PJ et al. 1989. M apping the genes for erythocytic alpha-spectrin 1 (SPTA1) and coagulation factor V (F5). Cytog. Cell. Genet. 51:1.042.

M cGuireW et al. 1999. Severe malarial anemia and cerebral malaria are associated with different tumor necrosis factor promoter alleles. Journal Infect. Dis. 179: 287-290.

M enard R, Sultan AA, Corte C, Altzuler R, van Dijk M R, Janse CJ, W aters AP, N ussenzweig RS \& N ussenzweig $V$ 1997. Circumsporozoite protein is required for development of malaria parasite in mosquitoes. $\mathrm{N}$ ature 385(6614):436-440.

Miller LH, M ason SJ, Clyde DF \& M cGinniss M H 1976. The resistance factor to Plasmodium vivax in blacks: the Duffy blood group genotype, FyFy. N. Engl. J. M ed. 295:302-304.

M odiano D et al. 1996a. Different response to Plasmodium falciparum malaria in West African sympatric ethnic group. Proc. N atl. Acad. Sci. USA 93:13.20613.211.

M odiano D et al. 1996b. Different response to Plasmodium falciparum in West African sympatric ethinic groups: possible implications for malaria control strategies. Parassitologia 41 (1-3):193-197.

M odiano D et al. 2001. The lower susceptibility to Plasmodium falciparum malaria of Fulani of Burkina Faso (West Africa) is associated with low frequencies of classic malaria-resistance genes. Trans. Royal. Soc. Trop. M ed. Hyg. 95:149-152.

Modiano D et al. 2001. Hemoglobin C protects against clinical Plasmodium falciparum malaria. Nature 414:305-308.

M otta M M , Thathy V, N ussenweig RS \& N ussenzweig V 2001. Gene targeting in the rodent malaria parasite Plasmodium yoelii. M ol. Biochem. Parasitol. 113(2): 271-278.

Mourant AE, Kopec AC \& Domaniewska-Sobczak K 1976. The distribution of human groups and other polymorphisms (2a ed.). Oxford University Press, Londres.

Nagel RL 1990. Innate resistance to malaria: The intraerytrocytic cicle. Blood Cells 16: 321-339.

Nagesha HS et al., 2001. M utations in the pfmdr1, dhfr and dhps genes of Plasmodium falciparum are associated with in-vivo drug resistance in West Papua, Indonesia. Trans. R. Soc. Trop. M ed. Hyg. 95(1): 43-49.

N eote K, M ak JY, Kolakoski LF \& Schall T 1994. Functional and biochemical analysis of the cloned Duffy antigen: identity with the red blood cell chemokine receptor. Blood 84 (1): 44-52.

Newbold C, Craif A, Kyes A et al. 1999. Plasmodium falciparum: pathogenesis, polimorphism and the infected red cell surface. Transf. Clinique et biologique 6: 57-60

Nogueira PA, W underlich G \& Pereira da Silva LH 2001. Variant antigens of Plasmodium falciparum encoded by the var multigenic family are multifunctional 
macromolecules. Res. M icrobiol. 152: 141-147.

N omura T et al. 2001. Evidence for different mechanisms of chloroquine resistance in 2 Plasmodium species that cause human malaria. J. Infect. Dis. 183(11): 1.653-1.661.

N ussenzweig V \& N ussenzweig RS 1989. Rationale for the development of na engineered sporozoïte malaria vaccine. Advances Immunol. 45: 283-334.

Parasol N, Reid M, Rios M, Castillo L, H arari I \& Kosower NS 1998. A novel mutation in the coding sequence of the FY*B allele of the Duffy chemokine receptor gene is associated with an altered erythrocyte phenotype. Blood 92 (7):2.237-2.243.

Perera KL et al. 1998. Baculovirus merozoite surface protein $1 \mathrm{C}$-terminal recombinant antigens are highly protective in a natural primate model for human Plasmodium vivax malaria. Infect. Immun. 66(4): 1.500-1.506.

Pessoa S 1946. Parasitologia médica. (1a ed.). Editora Guanabara, São Paulo.

Peterson DS, M iller LH \& W ellems TE 1995. Isolation of multiple sequences from the Plasmodium falciparum genome that encode conserved domains homologous to those of erythrocyte-binding proteins. Proc. N atl. A cadem. Sci. USA 92(15): 7.100-7.104.

Reed M B et al. 2000. Targeted disruption of na erythrocyte binding antigen in Plasmodium falciparum is associated with a switch toward a sialic acid-independent pathway of invasion. Proc. N atl. Acad. Sci. USA 97(13): 7.509-7.514.

Smith JD et al., 2000. Identification of a Plasmodium falciparum intercellular adhesion molecule-1 binding domain : a parasite adhesionntrait implicated in cerebral malaria. Proc. Natl. Acad. Sci. USA. 97:1.7661.771.

Soper EL \& Wilson DB 1943. Anopheles gambiae in Brazil, 1930-1940. Rockefeller Foundation, N ova York, 261p.

Sultan AA et al. 1996. TRAP is necessary for gliding motility and infectivity of Plasmodium sporozoites. Cell 90: 511-522.

Telen MJ 2000. Red blood cell surface adhesion molecules: their possible roles in normal human physiology and disease. Seminars Hematol. 37 (2):130-132.

Thompson JK, Triglia T, Reed M B \& Cowman AF 2001. A novel ligand from Plasmodium falciparum that binds to a sialic acid-containing receptor on the surface of human erythrocytes. M ol. M icrobiol. 41(1): 47-58.

Tomas AM , Margos G, Dimopoulos G et al. 2001. P25 and P28 proteins of the malaria ookynete surface have multiple and partially redundant functions. EM BO J. 20(15): 3.975-3.983.

Tournamille C, Colin Y, Cartron JP \& Le Van Kim C 1995. Disruption of a GATA motif in the Duffy gene promoter abolishes erythroid gene expression in Duffynegative individuals. N ature Genetics 10 , june:224228

Triglia T et al. 2000. Apical membrane antigen 1 plays a central role in erythrocyte invasion by Plasmodium species. M ol. M icrobiol. 38(4):706-718.

Udomsangpetch R, Todd J, Carlson J \& Greenwood BM 1993. The effect of hemoglobin genotype and $A B O$ blood groups on the formation of rosettes by Plasmodium falciparum infected red blood cells. Am. J. Trop. M ed. Hyg. 48(2):149-153.

Van Dijk M R, W aters AP \& Janse CJ 1995. Stable transfection of malaria parasite blood stages. Science 268:1.358-1.362.

Vasconcelos KF et al., 2000. M utation in Plasmodium falciparum dihydrofolate reductase and dihydropteroate synthase of isolates from the Amazon Region of Brazil. M em. Inst. O swaldo C ruz 95(5):721-728.

Vieira PP et al. 2001. Analysis of the PfCRT k76T mutation on Plasmodium falciparum isolates from the Amazon Region of Brazil. J. Inf. Dis. 183:1.832-1.833.

Vizioli J et al. 2001. Gambicin: a novel immune responsive antimicrobial peptide from the malaria vector Anopheles gambiae. Proc. Natl. Acad. Sci. USA $98(22): 12.630-12.635$.

Wellems TE \& Plowe CV 2001. Chloroquine-resistant malaria. J. Infect. Dis. 184(6): 770-776.

Wellems TE, Walker-Jonah A \& Panton LJ 1991. Genetic mapping of the chloroquine-resistance locus on Plasmodium falciparum chromosome 7. Proc. Natl. Acad. Sci. USA 88(8):3.382-3.386.

Wertheimer SP \& Barnwell JW 1989. Plasmodium vivax interaction with the human Duffy blood group glycoprotein: Identification of a parasite-like protein. Exp. Parasitol. 69:340-350.

Wu Y, Kirkman LA \& W ellems TE 1996. Transformation of Plasmodium falciparum malaria parasites by homologous integration of plasmids that confer resistance to pyrimethamine. Proc. Natl. Academ. Sci. USA 93(3):1.130-1.134

Zimmerman PA et al. 1999. Emergence of $F Y^{*} A$ null in a Plasmodium vivax-endemic region of Papua $\mathrm{New}$ Guinea. Proc. Natl. Acad.Sci. (USA) 96(24):13.97313.977. 